\title{
Level of Adherence to Cytotoxic Drugs by Breast Cancer Patients' in Lagos State University Teaching Hospital
}

\author{
Popoola Abiodun ${ }^{*}$, Samira Makanjuola², Sowunmi Anthonia ${ }^{3}$, Igwilo Adaeze ${ }^{1}$, Mobolaji \\ Oludara ${ }^{2}$, Ibrahim Nasir ${ }^{4}$, Omodele Foluso ${ }^{4}$ \\ ${ }^{1}$ Oncology Unit, Department of Radiology, Lagos State University College of Medicine, Ikeja, Nigeria \\ ${ }^{2}$ Department of Pharmacology, Lagos State University College of Medicine, Ikeja, Nigeria \\ ${ }^{3}$ Department of Radiotherapy, Lagos University Teaching Hospital, Idiaraba, Nigeria \\ ${ }^{4}$ Department of Surgery, Lagos State University Teaching Hospital, Ikeja, Nigeria \\ Email: ${ }^{*}$ pabiodun2001@yahoo.com
}

Received 8 March 2015; accepted 24 April 2015; published 30 April 2015

Copyright (C) 2015 by authors and Scientific Research Publishing Inc.

This work is licensed under the Creative Commons Attribution International License (CC BY).

http://creativecommons.org/licenses/by/4.0/

c) (i) Open Access

\section{Abstract}

Background: Breast cancer is one of the most common malignant diseases in women and adjuvant combination chemotherapy has been shown to reduce mortality from this disease. Adherence to medical treatment is a multifaceted issue that can substantially alter the outcomes of therapy. Patient non-adherence to chemotherapy is the ultimate barrier to the treatment effectiveness. Objective: This study was carried out to determine the relationship between cancer chemotherapy adherence and breast cancer staging, patient's perception of cancer care and patient's socio-demographic characteristics. Material and method: This was a cross sectional study selection of respondents and was based on simple random sampling technique, 184 patients were interviewed and data was collected using a semi-structured questionnaire to obtain socio-demographic data, adherence data, and facility-related information. Results: There was a significant association between marital status and non-adherence $(P=0.013)$. Both separated and single subjects had higher proportion of non-adherence compared with married subjects. Analysis of perception of chemotherapy care revealed a significant association between the satisfaction score and non-adherence, with non-adherent patients showing higher scores or being less satisfied. The quality of service $(P=0.0052)$; rating of needs been met $(P=0.0079)$; rating on whether the services helped the subject $(P=0.0405)$; rating on the general satisfaction of the services provided $(P=0.0115)$; and rating on whether subject would seek help again $(P=0.0320)$ all had a significant association with non-adherence. Conclusion: The awareness of oncologist and patient of the problem of nonadherence and communication regarding the importance of adherence to therapy may improve health outcomes.

\footnotetext{
${ }^{*}$ Corresponding author.
} 


\section{Keywords}

\section{Chemotherapy, Adherence, Breast Cancer}

\section{Introduction}

Breast cancer is one of the most common malignant diseases in women. There are greater than 1,000,000 new cases diagnosed annually worldwide. A marked increase in incidence occurs annually and especially among women of young age, which poses a serious threat to women's physical and mental health [1]. Studies from Nigeria indicate that the breast cancer is the most common female malignancy [2].

Surgery followed by adjuvant treatment has been the gold standard for breast cancer treatment for a long time. More recently, neoadjuvant treatment has been recognized as an important strategy in biomarker and target evaluation. It is clinically indicated for patients with large tumor size, high nodal involvement and an inflammatory component, or for those wish to preserve remnant breast tissue [3].

Adjuvant combination chemotherapy has been used since the 1970s for subgroups of women with early stages of breast cancer and has been shown to reduce mortality from this disease [4].

Adherence to medical treatment is a complex and multifaceted issue that can substantially alter the outcomes of therapy. Non-adherence can contribute greatly to the variability observed in a drug's therapeutic effect, with the potential for a clinician to attribute the patient's worsening condition to an absence of drug activity [5]. Patient non-adherence to chemotherapy is the ultimate barrier to the treatment effectiveness [6]. Adherence is the extent to which a patient's behavior coincides with medical advice [7]. Because barriers to medication adherence are complex and varied, solutions to improve adherence must be multifactorial [8] [9]. There is paucity of information on adherence to cancer chemotherapy among the Nigerian population unlike disease conditions like HIV/AIDS and tuberculosis where some published works exist. Anyanwu et al. had reported poor compliance and adherence to treatment modalities offered breast cancer patients over a five year period in Eastern Nigerian. This report, however, did not evaluate what factors were responsible for the poor adherence reported. This study is therefore intended to fill some of these knowledge gaps with the following objectives (Table 1 and Table 2):

1) To determine the relationship between cancer chemotherapy adherence and breast cancer staging.

2) To determine the relationship between cancer chemotherapy adherence and patient's perception of cancer care.

3) To determine the relationship between cancer chemotherapy adherence and patient's socio-demographic characteristics.

\subsection{Methodology}

This is a cross sectional study that was carried out amongst female breast cancer patients attending the oncology clinic of Lagos State University Teaching Hospital. Selection of respondents was based on simple random sampling technique.

A total number of 184 patients were interviewed.

Inclusion criteria:

1) Adults: 18 years old and above.

2) Histological diagnosis of breast cancer.

\begin{tabular}{cccc}
\hline $\begin{array}{c}\text { Table 1. Chemotherapy adherence. } \\
\text { Level of adherence }\end{array}$ & Frequency & Percentage (\%) & Cumulative (\%) \\
\hline Adherent & 116 & 71.17 & 71.17 \\
Missed 1 dose & 36 & 22.09 & 93.25 \\
Missed 2 or more doses & 5 & 3.07 & 96.32 \\
Missed whole cycle & 4 & 2.45 & 98.77 \\
Dose at irregular interval & 2 & 1.23 & 100.00 \\
\hline
\end{tabular}


Table 2. Factors associated with adherence.

\begin{tabular}{|c|c|c|c|c|}
\hline \multicolumn{2}{|c|}{ Factors } & Adherent & Miss $\geq 1$ dose & $P$-value \\
\hline \multirow{4}{*}{ Marital status } & Married & 87 (76.99\%) & 26 (23.01\%) & \multirow{4}{*}{$P=0.013$} \\
\hline & Separated & $3(42.86 \%)$ & $4(57.14 \%)$ & \\
\hline & Single & $11(47.83 \%)$ & $12(52.17 \%)$ & \\
\hline & Widowed & 15 (75.00\%) & $5(25.00 \%)$ & \\
\hline \multirow{5}{*}{ Income } & $>\mathrm{N} 10,000$ & 20 (71.43\%) & $8(28.57 \%)$ & \multirow{5}{*}{$P=0.851$} \\
\hline & N10-25,000 & $30(73.17 \%)$ & $11(26.83 \%)$ & \\
\hline & N26-50,000 & $13(61.90 \%)$ & $8(38.10 \%)$ & \\
\hline & N51-100,000 & $8(66.67 \%)$ & $4(33.33 \%)$ & \\
\hline & $>\mathrm{N} 100,000$ & $6(85.71 \%)$ & $1(14.29 \%)$ & \\
\hline \multirow{5}{*}{ Education } & None & $14(70.00 \%)$ & $6(30.00 \%)$ & \multirow{5}{*}{$P=0.602$} \\
\hline & Primary & 20 (66.67\%) & $6(33.33 \%)$ & \\
\hline & Secondary & 45 (78.95\%) & 12 (21.05\%) & \\
\hline & Graduate & 26 (60.47\%) & 17 (39.53\%) & \\
\hline & Post-graduate & $6(75.00 \%$ & $2(25.00 \%)$ & \\
\hline \multirow{3}{*}{ Employment status } & Self-employed & 59 (71.08\%) & 24 (28.92\%) & \multirow{3}{*}{$P=0.694$} \\
\hline & Unemployed & $21(63.64 \%)$ & 12 (36.36\%) & \\
\hline & Worker & 28 (71.79\%) & $11(28.21 \%)$ & \\
\hline \multirow{4}{*}{ Stage } & Stage I & $10(76.92 \%)$ & $3(28.08 \%)$ & \multirow{4}{*}{$P=0.318$} \\
\hline & Stage II & 20 (71.43\%) & $8(28.57 \%)$ & \\
\hline & Stage III & $9(75.00 \%)$ & $3(25.00 \%)$ & \\
\hline & Stage IV & $3(37.50 \%)$ & $5(62.50 \%)$ & \\
\hline \multirow{4}{*}{$\begin{array}{l}\text { Did you receive good } \\
\text { quality service? }\end{array}$} & Yes, definitely & 31 (88.57\%) & $4(11.43 \%)$ & \multirow{4}{*}{$P=0.0052$} \\
\hline & Yes, generally & 65 (69.89\%) & $28(30.11 \%)$ & \\
\hline & No, not really & 15 (62.50\%) & $9(37.50 \%)$ & \\
\hline & No, definitely not & $0(0.00 \%)$ & 2 (100.00\%) & \\
\hline \multirow{4}{*}{$\begin{array}{c}\text { Have the service } \\
\text { provided helped you? }\end{array}$} & Yes, definitely & 80 (76.19\%) & 25 (23.81\%) & \multirow{4}{*}{$P=0.0405$} \\
\hline & Yes, generally & $26(61.90 \%)$ & $16(38.10 \%)$ & \\
\hline & No, not really & $2(50.00 \%)$ & 2 (50.00\%) & \\
\hline & No, definitely not & $1(50.00 \%)$ & $1(50.00 \%)$ & \\
\hline \multirow{4}{*}{$\begin{array}{l}\text { Are you satisfied with } \\
\text { the care received? }\end{array}$} & Yes, definitely & 60 (78.95\%) & 16 (21.05\%) & \multirow{4}{*}{$P=0.0115$} \\
\hline & Yes, generally & $41(68.33 \%)$ & 19 (31.67\%) & \\
\hline & No, not really & $5(50.00 \%)$ & $5(50.00 \%)$ & \\
\hline & No, definitely not & $1(25.00 \%)$ & $3(75.00 \%)$ & \\
\hline \multirow{4}{*}{$\begin{array}{l}\text { Would you seek } \\
\text { help again? }\end{array}$} & Yes, definitely & 66 (77.65\%) & 19 (22.35\%) & \multirow{4}{*}{$P=0.0320$} \\
\hline & Yes, generally & 30 (54.55\%) & $25(45.45 \%)$ & \\
\hline & No, not really & $3(100.00 \%)$ & $0(0.00 \%)$ & \\
\hline & No, definitely not & 2 (100.00\%) & $0(0.00 \%)$ & \\
\hline
\end{tabular}




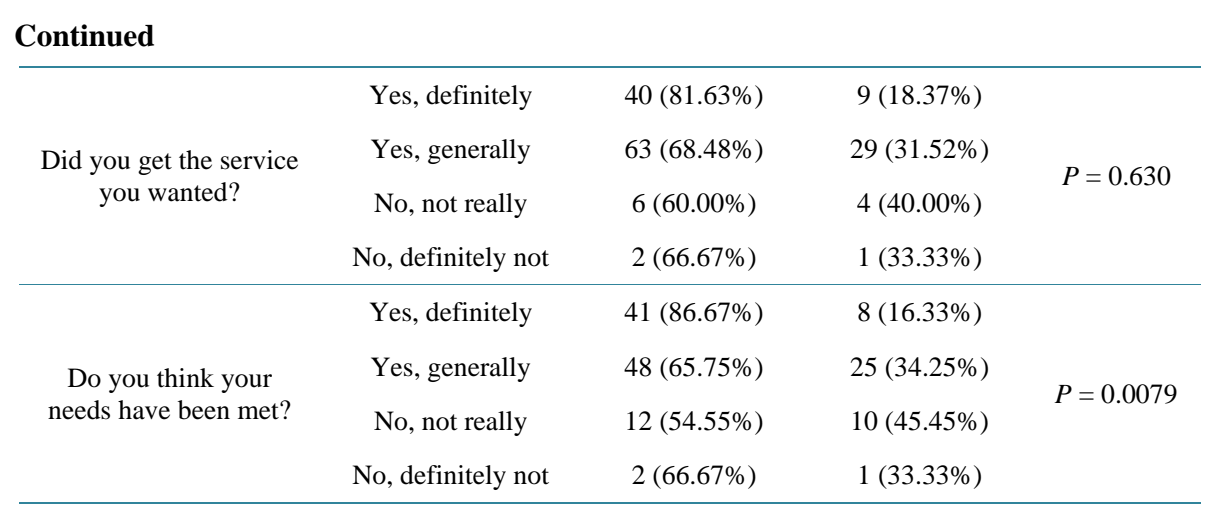

3) At least 3 months history of breast cancer management at oncology clinic, LASUTH.

Exclusion criteria:

1) Patients with depression, cognitive impairment or psychiatric disorder.

Independent variables:

1) Staging of breast cancer.

2) Patient's perception of cancer care at LASUTH.

3) Socio-demographic characteristics of study subjects.

Dependent variable: Level of adherence to cancer chemotherapy.

Data was collected by a trained interviewer who administered a semi-structured questionnaire to obtain sociodemographic data, adherence data, and facility-related information. Adherence data collection was based on the definition by the International Society for Pharmacoeconomics and Outcome Research stating that adherence referred to the degree or extent of conformity to the recommendations about day-to-day treatment by the provider with respect to the timing, dosage, and frequency; and the duration of time from initiation of the medication to the discontinuation of therapy [9].

\subsection{Statistical Analysis}

Each variable was analyzed in relation to adherence first, using Chi-Square analysis test. If significant, variables were then further analyzed in relation to non-adherence using the Two-sample Wilcoxon rank-sum (Mann Whitney).

\section{Results}

Socio-demographic characteristics of study subjects, staging of breast cancer at diagnosis and patient's perception of cancer care at LASUTH were analyzed in relation to the levels of adherence to chemotherapy.

- The analysis between socio-demographic characteristics of subjects here studied and their level of adherence to chemotherapy care revealed a significant association between marital status and non-adherence $(P=0.013)$ (Figure 1 and Figure 2). Both separated and single subjects had higher proportion of non-adherence compared to married subjects. The remaining socio-demographic factors including education, income, and employment status had no significant association with non-adherence to chemotherapy treatment (Figure 3).

- Stage of the breast cancer at diagnosis also revealed no significant association with non-adherence to chemotherapy, although it should be noted that stage at diagnosis was not available for approximately $67 \%$ (122) of subjects.

- Analysis of perception of chemotherapy care revealed a significant association between the satisfaction score and non-adherence with non-adherent patients showing higher scores or being less satisfied. The quality of service $(P=0.0052)$; rating of needs been met $(P=0.0079)$; rating on whether the services helped the subject $(P=0.0405)$; rating on the general satisfaction of the services provided $(P=0.0115)$; and rating on whether subject would seek help again $(P=0.0320)$ all had a significant association with non-adherence.

\section{Discussion}

Breast cancer outcomes to improve with 5 years survival rate having increased from $50 \%$ in the 1970 s to nearly 


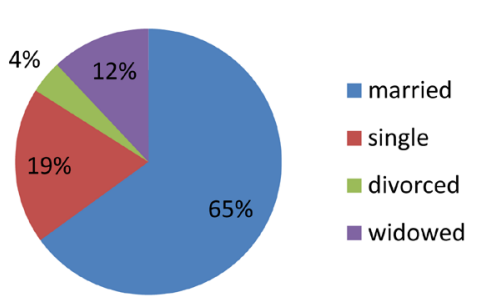

(a)

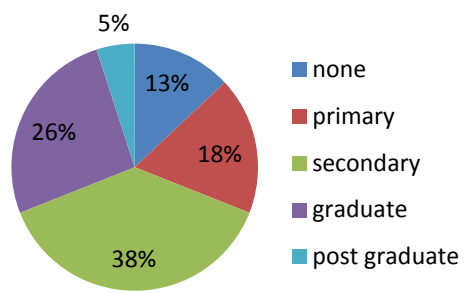

(c)

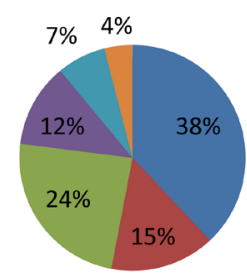

unknown

- < $1 \mathrm{~N} 10,000$

- N10-25,000

- N26-50,000

- N51-100,000

모 >N100,000

(b)

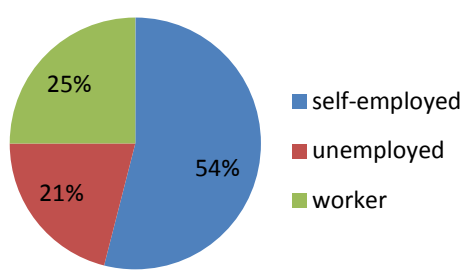

(d)

Figure 1. Illustration of social-demographic features of breast cancer patients including: (a) marital status; (b) income; (c) education level; and (d) employment status.

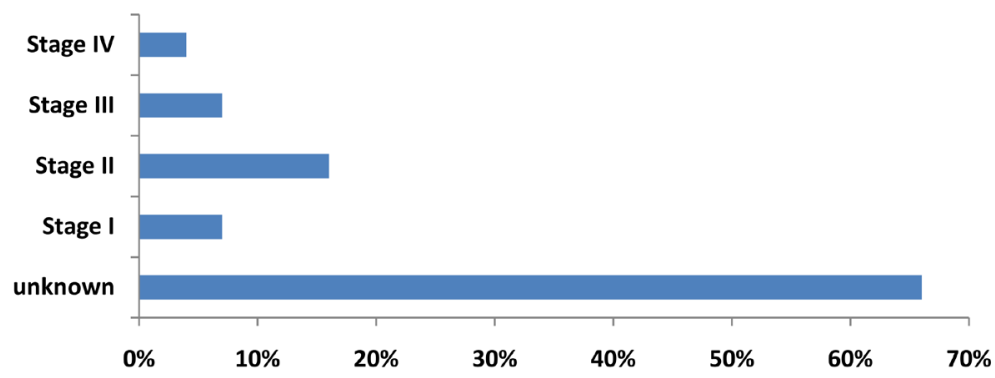

Figure 2. Illustration of tumour characters: stage of breast cancer at diagnosis.

Are you satisfied with the service provided

Would you seek help again

Did you receive good quality service

Do you think your needs have been met

Have the service provided helped you

Did you get the type of service you want
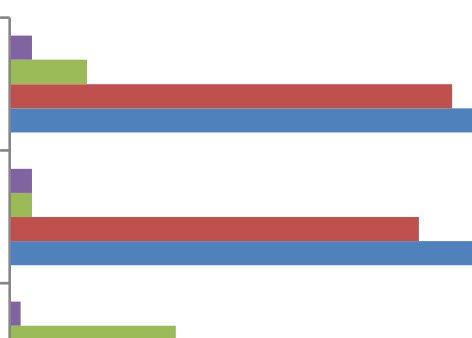

\section{$-$}
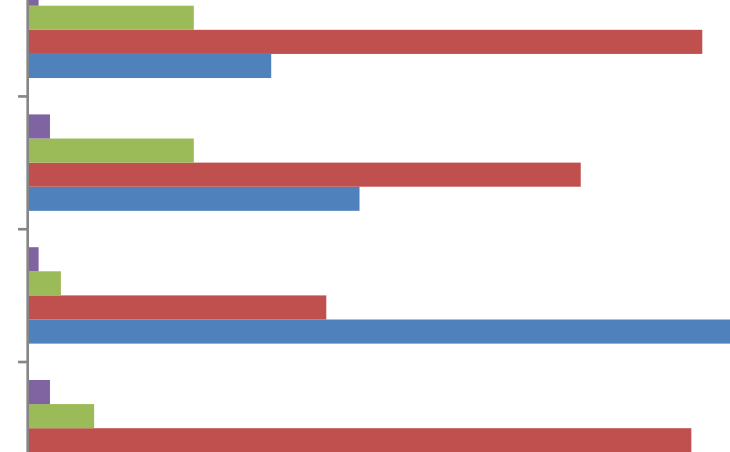

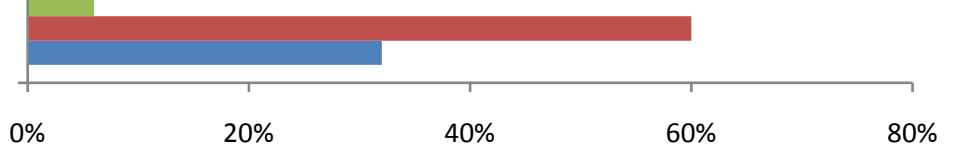

Figure 3. Illustration of perception of chemotherapy care. 
$80 \%$ today with major contributions made by the advent of screening and improved systemic therapy such as the use of anti-oestrogen, chemotherapy and trastuzumab [10]. In the absence of good adherence, therapeutic goals cannot be achieved resulting in poorer outcomes as adherence has been cited as the single most important modification factor that compromises treatment outcome across disease [11].

The marital status in socio-demographic characteristic of the study subject has been found to influence the pattern of adherence to chemotherapy $(P=0.013)$. Both separated and single patients had higher proportion of non-adherence compared to married patients.

It has been revealed that emotional support influences the decision women make to adhere to treatment. Emotional support is the most beneficial in the adjustment of women with breast cancer, generating opportunities for them to express feelings and favouring treatment adherence. Spouse has been found out the most important emotional support and the main source of instrumental support [12].

This corroborate study by Arora et al. reported that emotional support could influence and/or facilitate decisions concerning treatment adherence and post treatment care contributing to health promotion [13].

The remaining socio-demographic factors such as education, income and employment status had no association with non-adherence to chemotherapy treatment in this study.

In a study on African-American women, Sheppard et al. [14] noted that barriers to treatment could include not only limited knowledge of cancer and its causes, but also lack of health insurance, influence of spiritual beliefs and need for secrecy and complementary and alternative treatment. So level of education may not actually in-

fluence level of adherence in Nigeria [15].

In most studies, the financial status of the patients have been associated with level of adherence to chemotherapy with low income associated with non adherence, as stated by Arowolo et al. in his study where $45 \%$ of patients who gave reasons for non adherence to chemotherapy cited financial constrain as the problem, while overuse was found in patients with high income [16].

In our study, level of income does not have significant associations with non adherence probably because of the financial support programme of Lagos State Ministry of Health where indigent patient are supported with funds to purchase their chemotherapy, supportive therapy and pre-chemotherapy investigations. This programme also includes free consultations for cancer patient. Interactions with medical care system which includes relationship with providers, satisfaction with care and convenience of clinics has been found to influence adherence significantly in this study.

Reeler et al. noted that there was an improvement in treatment of breast cancer in developing countries (Ethiopia) when a programme was developed to support infrastructure for the management of breast cancer that our studies contributed to this finding [17].

\section{Conclusion}

Patients who are non-adherent to adjuvant chemotherapy may be compromising their care. The awareness of oncologist and patient of the problem of non-adherence and communication regarding the importance of adherence to therapy may improve health outcomes.

\section{References}

[1] Qiao, E.Q., Ji, M.H., Wu, J.Z., Li, J., Xu, X.Y., Ma, R., Zhang, Z.H., He, Y.J., Zha, Q.B., Song, X., Zhu, L.W. and Tang, J.-H. (2013) Joint Detection of Multiple Immunohistochemical Indices and Clinical Significance in Breast Cancer. Molecular and Clinical Oncology, 1, 703-710.

[2] Popoola, A.O., Ogunleye, O.O., Ibrahim, N.A., Omodele, F.O. and Igwilo, A.I. (2012) Five Year Survival of Patients with Breast Cancer at the Lagos State University Teaching Hospital, Nigeria. Online Journal of Medicine and Medical Science Research, 1, 24-31.

[3] Miller, E., Lee, H.J., Lulla, A., Hernandez, L., Gokare, P. and Lim, B. (2014) Current Treatment of Early Breast Cancer: Adjuvant and Neoadjuvant Therapy. Version 1, F1000 Research, 3, 198.

[4] Brezden, C.B., Phillips, K.-A., Abdolell, M., Buston, T. and Tannock, I.F. (2000) Cognitive Function in Breast Cancer Patients Receiving Adjuvant Chemotherapy. Journal of Clinical Oncology, 18, 2695-2701.

[5] Partridge, A.H., LaFountain, A., Mayer, E., Taylor, B.S., Winer, E. and Asnis-Alibozek, A. (2008) Adherence to Initial Adjuvant Anastrozole Therapy among Women with Early-Stage Breast Cancer. Journal of Clinical Oncology, 26, 556-562. 
[6] Partridge, A.H., Archer, L., Kornblith, A.B., Gralow, J., Grenier, D., Perez, E., Wolff, A.C., Wang, X.F., Kastrissios, H., Berry, D., Hudis, C., Winer, E. and Muss, H. (2010) Adherence and Persistence with Oral Adjuvant Chemotherapy in Older Women with Early-Stage Breast Cancer in CALGB 49907: Adherence Companion Study 60104. Journal of Clinical Oncology, 28, 2418-2422.

[7] American College of Preventive Medicines (2011) Medication Adherence: Improving Health Outcomes. http://www.acpm.org/?MedAdhereTTProviders.

[8] Brown, M.T. and Bussell, J.K. (2011) Medication Adherence: WHO Cares? Mayo Clinical Proceedings, 86, 304-314. http://dx.doi.org/10.4065/mcp.2010.0575

[9] Cramer, J.A., Roy, A., Burrell, A., Fairchild, C.J., Fuldeore, M.J., Ollendorf, D.A. and Wong, P.K. (2008) Medication Compliance and Persistence: Terminology and Definitions. Value in Health, 11, 44-47.

[10] Wyld, L. (2013) The Optimal Approach to Early Breast Cancer. EJC Supplements, 11, 1-2. http://dx.doi.org/10.1016/j.ejcsup.2013.07.026

[11] Osterberg, L. and Blaschke, T. (2005) Adherence to medication. The New England Journal of Medicine, 353, $487-497$. http://dx.doi.org/10.1056/NEJMra050100

[12] Fernandes, A.F., Cruz, A., Moreira, C., Santos, M.C. and Silva, T. (2014) Social Support Provided to Women Undergoing Breast Cancer Treatment: A Study Review. Advances in Breast Cancer Research, 3, 47-53. http://dx.doi.org/10.4236/abcr.2014.32007

[13] Arora, N.K., Rutten, L.J.F., Gustafson, D.H., Moser, R. and Hawkins, R.P. (2007) Perceived Helpfulness and Impact of Social Support Provided by Family, Friends, and Health Care Providers to Women Newly Diagnosed with Breast Cancer. Psycho-Oncology, 16, 474-486. http://dx.doi.org/10.1002/pon.1084

[14] Sheppard, V.B., Christopher, J. and Nwabukwu, I. (2010) Breaking the Silence Barrier: Opportunity to Address Cancer in African-Born Women. Journal of the National Medical Association, 102, 461-468.

[15] Anyanwu, S.N.C., Egwuonwu, O.A. and Ihekwoaba, E.C. (2011) Acceptance and Adherence to Treatment among Breast Cancer Patients in Eastern Nigeria. Breast, 20, S51-S53. www.elsevier.com/brst

[16] Adisa, A.O., Lawal, O.O. and Adesunkanmi, A.R.K. (2008) Evaluation of Patients' Adherence to Chemotherapy for Breast Cancer. African Journal of Health Science, 15, 22-27.

[17] Reeler, A.V., Sikorayz, K. and Solomonx, B. (2008) Overcoming Challenges of Cancer Treatment Programmes in Developing Countries: A Sustainable Breast Cancer Initiative in Ethiopia. Clinical Oncology, 20, 191-198. 